NASA/TM-2000-209387

(1)

Investigation of Acoustic Fields for the Cassini Spacecraft: Reverberant Versus Launch Environments

William O. Hughes and Anne M. McNelis

Glenn Research Center, Cleveland, Ohio

Harry Himelblau

Rocketdyne/Boeing N.A., Canoga Park, California

\title{
Prepared for the
}

5th Aerocoustics Conference and Exhibit cosponsored by the American Institute of Aeronautics and Astronautics and the Confederation of European Aerospace Societies

Bellevue, Washington, May 10-12, 1999

National Aeronautics and Space Administration

Glenn Research Center 


\section{Acknowledgments}

The authors would like to acknowledge Lilo Bradford, Bruce Lowe and Lee Salem of LMA for their flight data reduction and analysis contributions to this paper. The authors acknowledge the following organizations and individuals for their outstanding contributions and support of Cassini acoustic test programs: LMA/Lilo Bradford, Bob Foster, Abe Jack, Tom Sayuk, Tom States; MDA/Theresa Armel, Bob Kessler, Mary Long, Mike Seely, George Stauffer; Analex Corporation/Evert Hurst; Cambridge Collaborative Inc./Jerome Manning, Ben Hebert; JPL/Thom Bergen, Paul Hardy, Dennis Kern; Aerospace Corp./Don Wong, Norm Lagerquist; RAL/John Kopec, Peter Strauss; NASA GRC/Pat Symons, Bill Taylor, James Robinson, Kuan Lee.

Available from

NASA Center for Aerospace Information 7121 Standard Drive

Hanover, MD 21076

Price Code: A03
National Technical Information Service 5285 Port Royal Road Springfield, VA 22100

Price Code: A03

Available electronically at http://gltrs.grc.nasa.gov/GLTRS 


\title{
Investigation of Acoustic Fields for the Cassini Spacecraft: Reverberant Versus Launch Environments
}

\author{
William O. Hughes* and Anne M. McNelis \\ National Aeronautics and Space Administration \\ Glenn Research Center \\ Cleveland, Ohio \\ Harry Himelblau** \\ Rocketdyne/Boeing N.A \\ Canoga Park, California
}

\section{Summary}

The characterization and understanding of the acoustic field within a launch vehicle's payload fairing (PLF) is critical to the qualification of a spacecraft and ultimately to the success of its mission. Acoustic measurements taken recently for the Cassini mission have allowed unique opportunities to advance the aerospace industry's knowledge in this field. Prior to its launch, the expected liftoff acoustic environment of the spacecraft was investigated in a full-scale acoustic test of a Titan IV PLF and Cassini simulator in a reverberant test chamber. A major goal of this acoustic ground test was to quantify and verify the noise reduction performance of special barrier blankets that were designed especially to reduce the Cassini acoustic environment. This paper will describe both the ground test and flight measurements, and compare the Cassini acoustic environment measured during launch with that measured earlier in the ground test. Special emphasis will be given to the noise reduction performance of the barrier blankets and to the acoustic coherence measured within the PLF.

\section{Introduction}

The Cassini spacecraft (see fig. 1) was developed at the Jet Propulsion Laboratory (JPL) and its suppliers for the National Aeronautics and Space Administration (NASA) to explore the planet Saturn, its rings, and its moons. NASA Lewis Research Center (LeRC, now John H. Glenn Research Center) performed the integration of the spacecraft to Lockheed-Martin Astronautics' (LMA) Titan IV launch vehicle. The spacecraft was launched on a Titan IV with a Centaur upper stage on October 15, 1997. Cassini will arrive at Saturn in July 2004.

The electric power sources for the Cassini mission are three critical Radioisotope Thermoelectric Generators (RTGs). The RTG design was previously vibration qualified for the Galileo and Ulysses missions. After extensive analysis of available Titan IV acoustic flight data, JPL analysts predicted that Cassini's RTG vibration responses to its acoustic environment would exceed the test qualified limits of the RTG design, due primarily to RTG mounting, launch vehicle and spacecraft differences.

To avoid an extremely costly requalification (estimated at \$30 Million) of the RTGs, a major blanket development and test effort was initiated and funded by NASA Glenn. Acoustic blankets are used in the PLF of expendable launch vehicles (ELVS) to reduce the interior acoustics and the subsequent vibration response of the spacecraft and its components. The new blankets that were developed and tested resulted in a lower and acceptable acoustic and vibration environment for the Cassini RTGs.

The wealth of acoustic data resulting from the blanket verification testing, coupled with mission unique flight measurements, allows an opportunity to compare the reverberant ground test environment with the actual liftoff environment for the spacecraft.

*Associate Fellow. AIAA.

**Member, AIAA. 


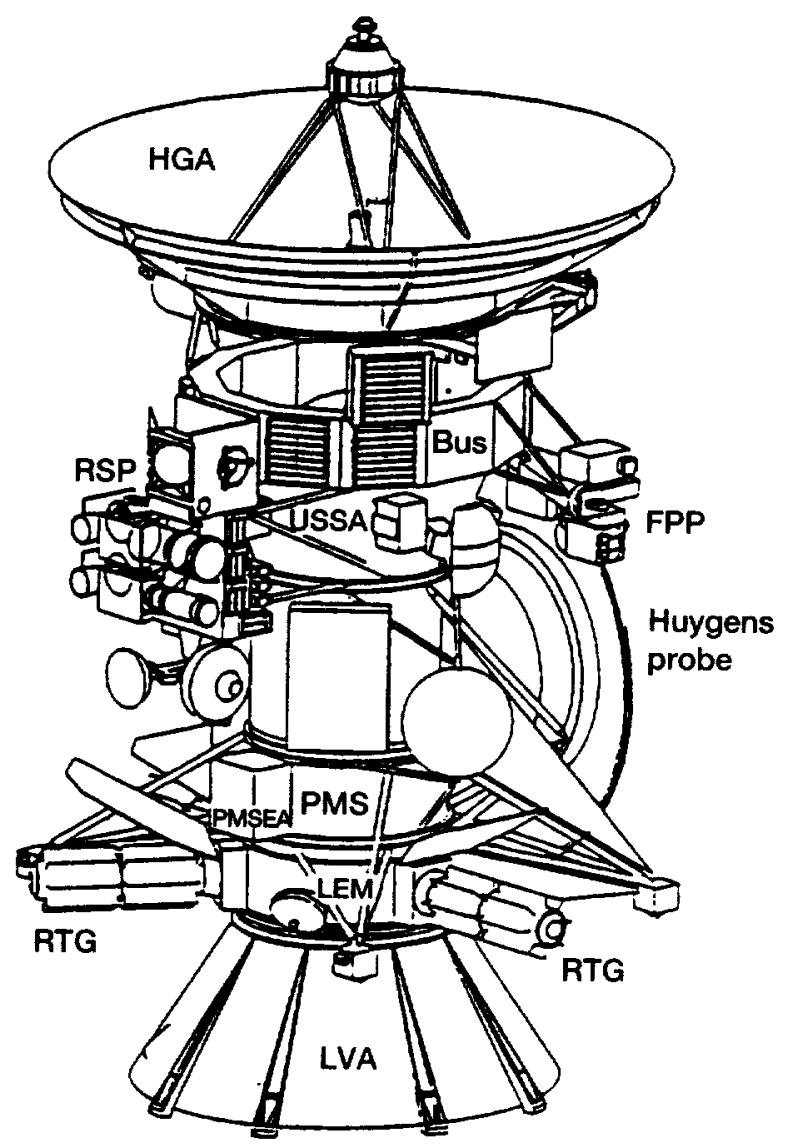

Figure 1.-Cassini Spacecraft. 8

\section{Acoustic Test Program Overview}

Acoustic blanket design technology for aerospace has seen little development in the past 25 years. To meet the needs of the Cassini mission it was necessary to develop advanced blanket technology. The blanket had to reduce the acoustic field significantly in the difficult frequency range of 200 to $250 \mathrm{~Hz}$. Typically, acoustic blankets are most effective at $400 \mathrm{~Hz}$ and above.

The goal was to reduce the acoustic environment for Cassini 's RTGs by $3 \mathrm{~dB}$ at 200 and $250 \mathrm{~Hz}$, compared with the environment provided by the baseline Titan IV blanket (3-in. thick, no internal barrier) system. A twophase test program was performed to develop and test verify the improved blankets.

Phase 1 consisted of evaluating new blanket designs by acoustic testing of flat panel blanket samples. Flat panel testing had the advantage that numerous designs could be quickly evaluated at relatively low cost. By proper interpretation of the absorption and transmission loss (TL) test data, the leading designs could then be chosen for further testing in Phase 2.

Phase 2 would test the leading candidate designs and the baseline Titan IV blanket design in a full-scale cylindrical PLF. Although this testing is expensive, the effect of the blankets on reducing the PLF interior acoustics would be measured with the appropriate flight-like boundary conditions and geometry. The need to verify the blanket's attenuation in a full-scale test was heightened by the fact that the frequency range of interest coincided with the ring frequency of the PLF's cylindrical section. 


\section{Summary of Flat Panel Testing}

Testing (refs. 1 and 2) of the new blanket designs in a flat panel configuration occurred in March-April 1994 at the Riverbank Acoustical Laboratory (RAL), Geneva, IL. Blanket absorption and TL values were obtained from reverberation time tests per ASTM C423 and from testing per ASTM E90, respectively. The absorption and TL data were used to analytically predict the effect of each design in reducing the PLF interior acoustics.

A total of 19 different blankets ( 18 new designs and the Titan IV baseline) were tested. Each blanket tested was an 8 - by 9 -ft rectangular sample. All materials utilized had to be already flight qualified.

The noise reduction of the acoustic blankets was investigated in the flat panel testing, by varying the thickness and density of the fiberglass batting, and the density and location of an internal barrier.

Of the 18 new blanket designs, 4 designs appeared to provide the necessary acoustic reduction between 200 to $250 \mathrm{~Hz}$. Two designs, V5 (6-in. thick blanket and a heavy internal barrier) and V10 (5-in. thick blanket with two different batting densities and an even heavier internal barrier), were chosen for Phase 2 testing.

\section{Summary of Full Scale PLF Testing}

Phase 2 testing occurred in January-February 1995 at LMA`s Reverberant Acoustic Laboratory, Denver, CO. The test hardware consisted of a $60-\mathrm{ft}$ high section of a Titan IV PLF, with simulators of the Cassini and Centaur upper stage. The lower part of the spacecraft simulator was a high fidelity developmental test model (DTM) supplied by JPL. Included in the DTM were one RTG dynamic simulator and two RTG mass simulators. The upper part of the spacecraft simulator and the large High Gain Antenna (HGA) at the top of the spacecraft were simulators provided by LMA to represent the proper geometry and volume effects.

Phase 2 consisted of 7 acoustic tests and used 3 blanket designs (baseline, V10 and V5, fig. 2) to determine the acoustic and RTG vibration environments.

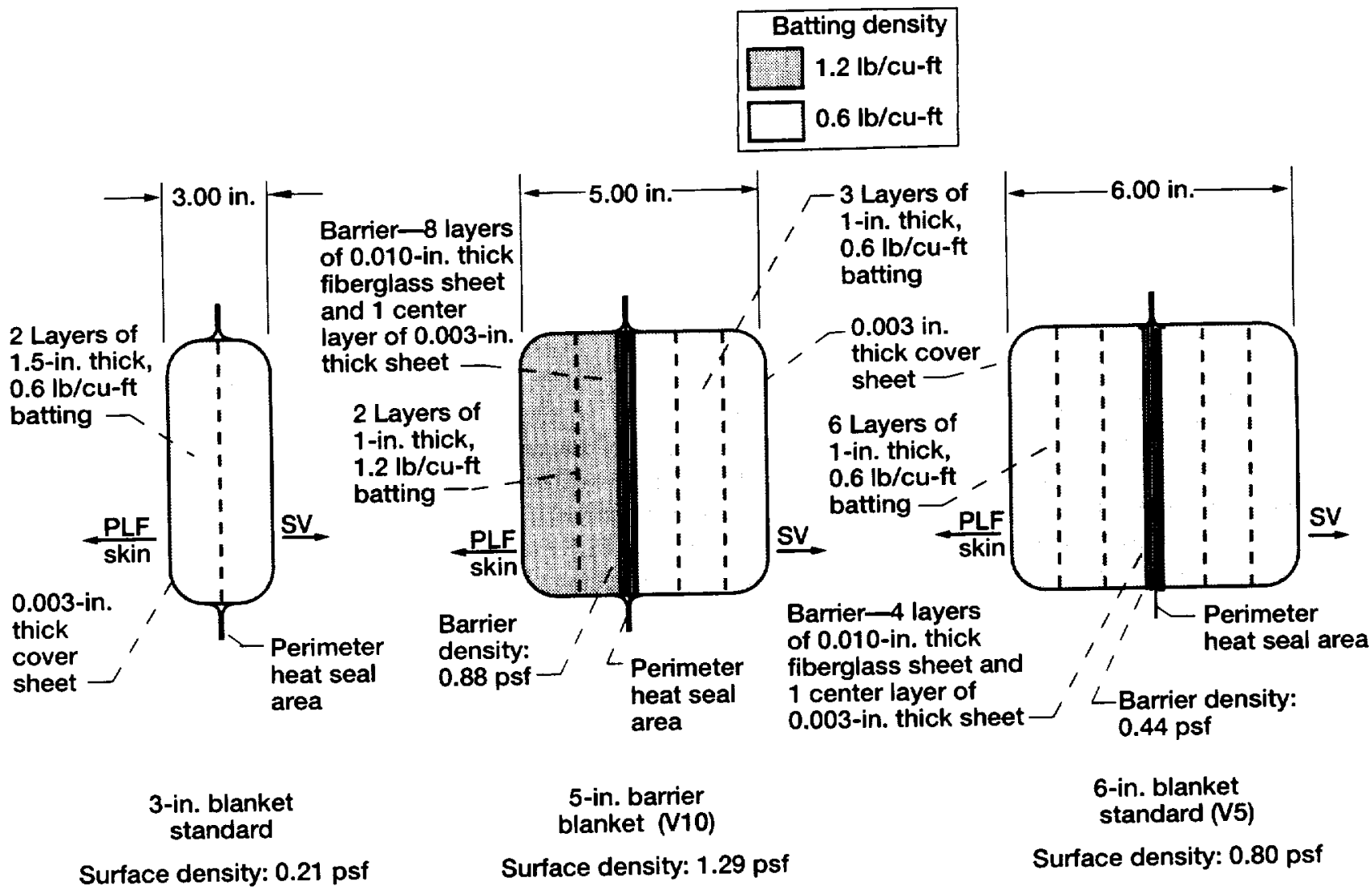

Figure 2.-Blanket designs used in Phase 2 testing. ${ }^{5}$ 


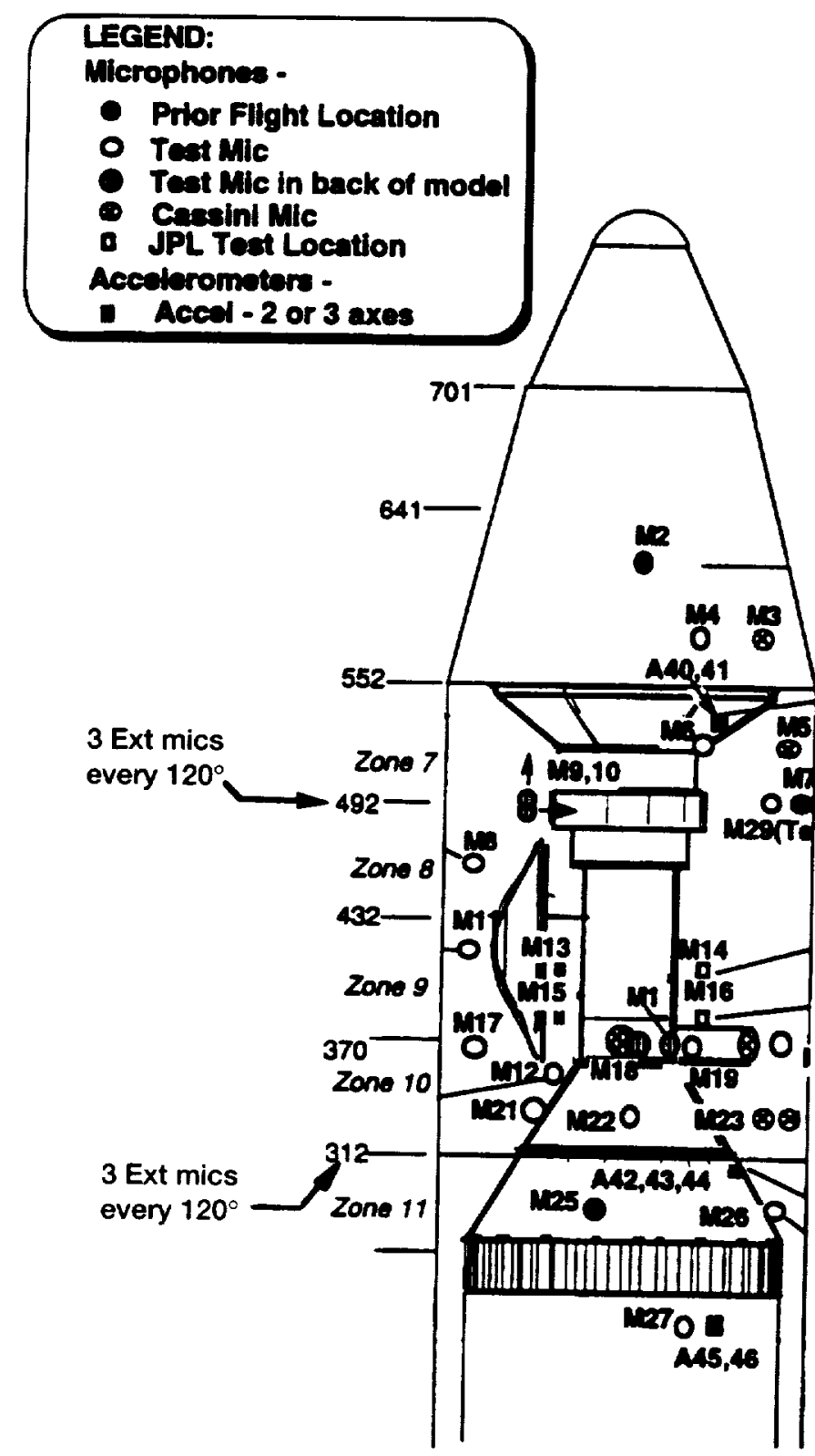

Figure 3.-Configuration and instrumentation locations for Phase 2 testing. ${ }^{5}$

From figure 4, one can see that the new blankets were very successful in reducing the PLF interior acoustics to levels below those provided by the baseline, using the desired PLF external specification. Test 2 data shows the average of 10 microphones in Zones 9 and 10, representing the average PLF interior level in the RTG region when the baseline blankets are utilized. Similarly Test 4 and 7 data represent the same microphone average when the V10 and V5 blankets, respectively, are substituted for the baseline, in Zones 8 to 11 .

Figure 5 illustrates the delta improvement for the V10 and V5 blankets. This figure shows that both blankets were successful in reducing the RTG acoustic environment by $3 \mathrm{~dB}$ at 200 and $250 \mathrm{~Hz}$. The improvement, positive at all frequencies, is largest between 200 to $400 \mathrm{~Hz}$.

The ultimate goal to reduce the RTG vibration response to prevent a vibration requalification test of the RTG was achieved. The acceleration power spectral density response at the base of the RTG dynamic simulator was substantially reduced, particularly at the desired frequencies, by utilizing either the V10 or V 5 blankets.

Among the many secondary objectives addressed during the Phase 2 acoustic testing were: (a) determining the effectiveness of the Cassini HGA in dividing the PLF interior into two distinct internal acoustics fields (the biconic 


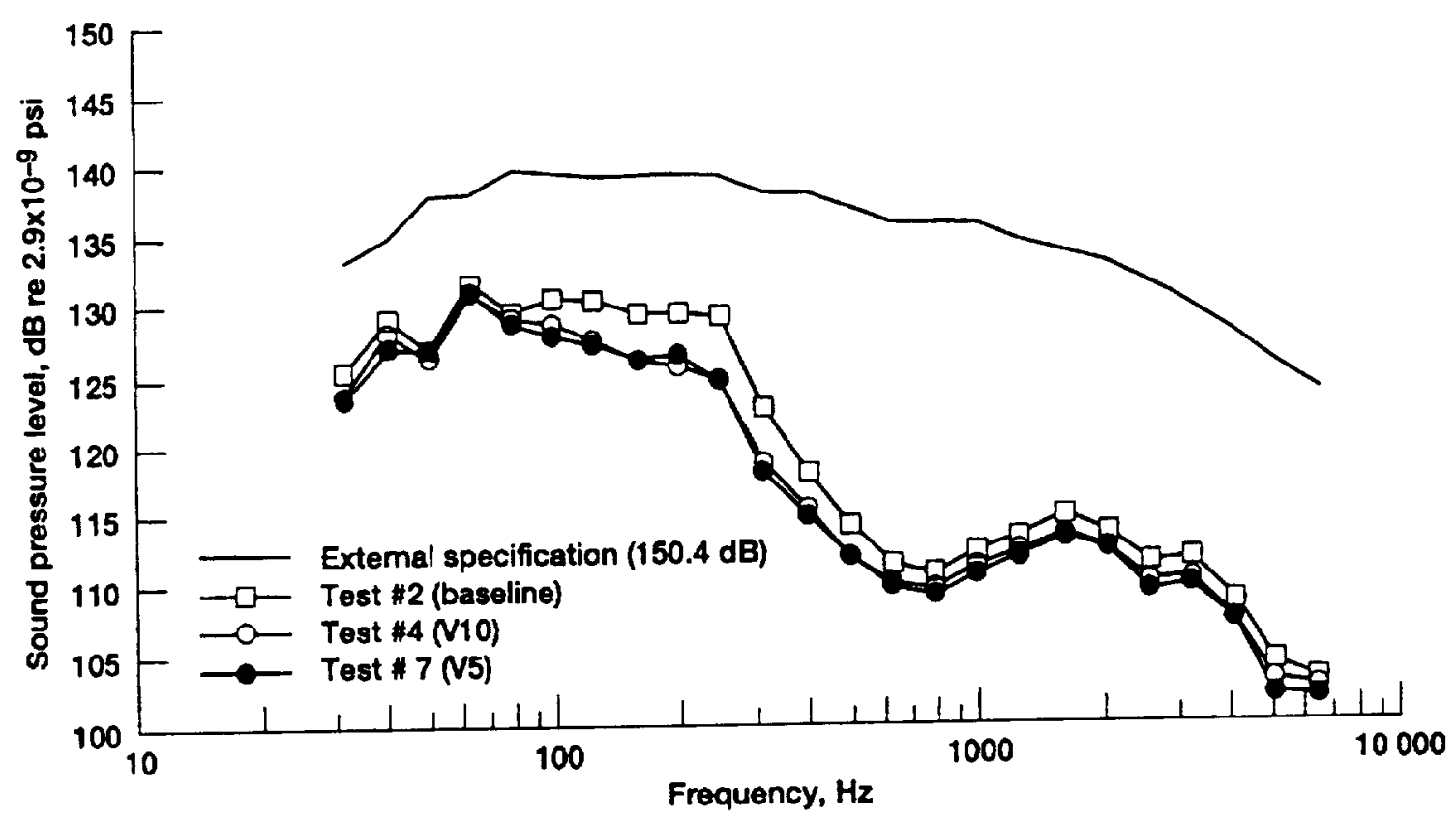

Figure 4.-Effect of blanket type on PLF interior acoustics. ${ }^{2}$

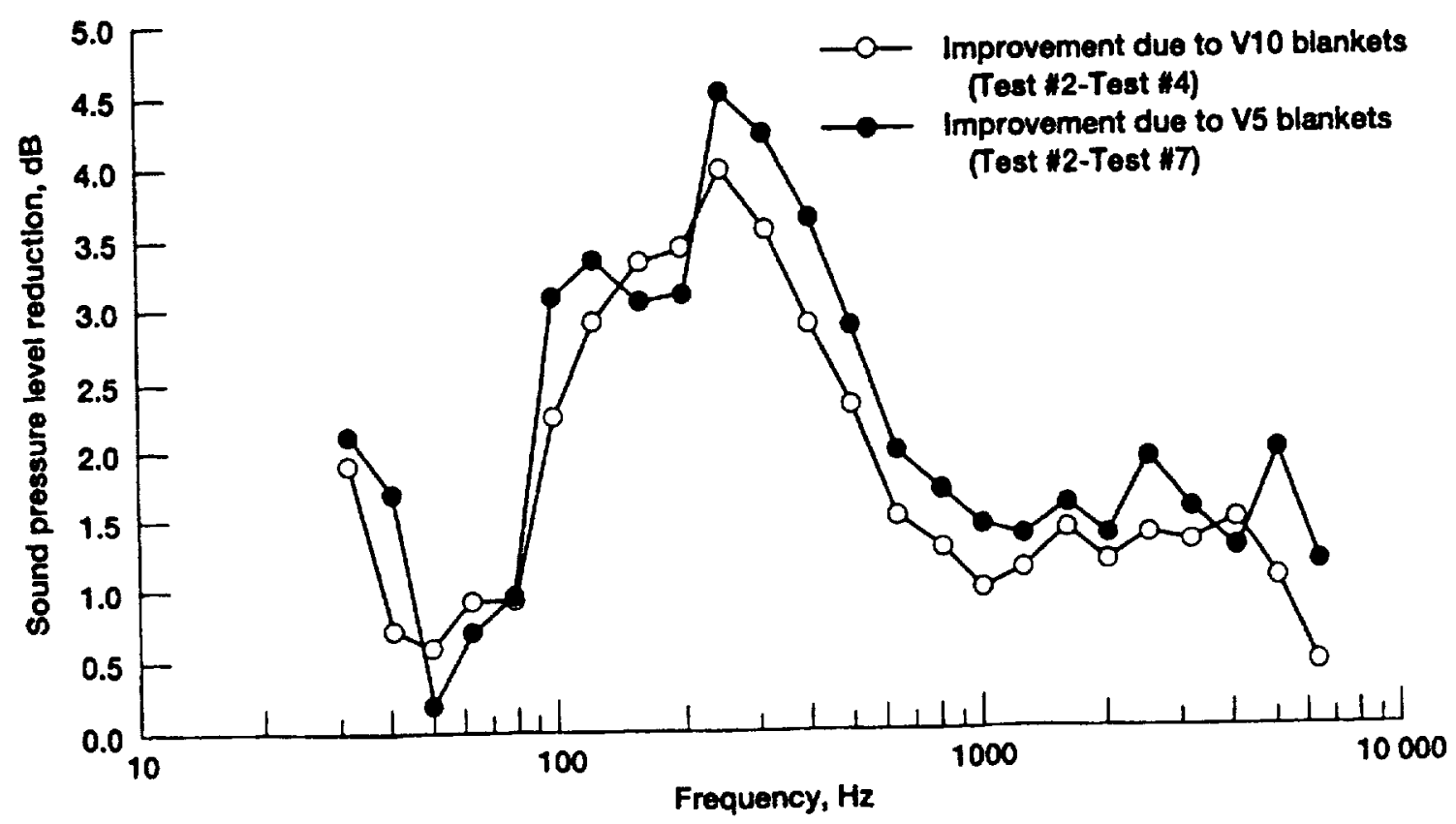

Figure 5.-Delta acoustic improvement using new blanket designs. ${ }^{2}$

and cylindrical sections above and below the HGA, respectively, and (b) determining the frequency range where the direct progressive acoustic field generated by the PLF exceeds the interior reverberant field, especially near the RTGs. Objective (a) addressed the issue of properly testing similar antennae and reflectors, whereas objective (b) addressed the definition of which type of acoustic field, progressive or reverberant, should be used for spacecraft testing. Ordinary coherence data analyses (ref. 3) were used.

Figure 6 shows low coherence $\left(\gamma^{2}{ }_{(4.6)}<0.75\right)$ for microphone pair $(4,6)$, identified in figure 3 , located close to and on opposite sides of the HGA, indicating two distinct fields. Thus, proper testing of the HGA should have been performed using two independent random sound sources, each with its own spectrum and confined to its own side 

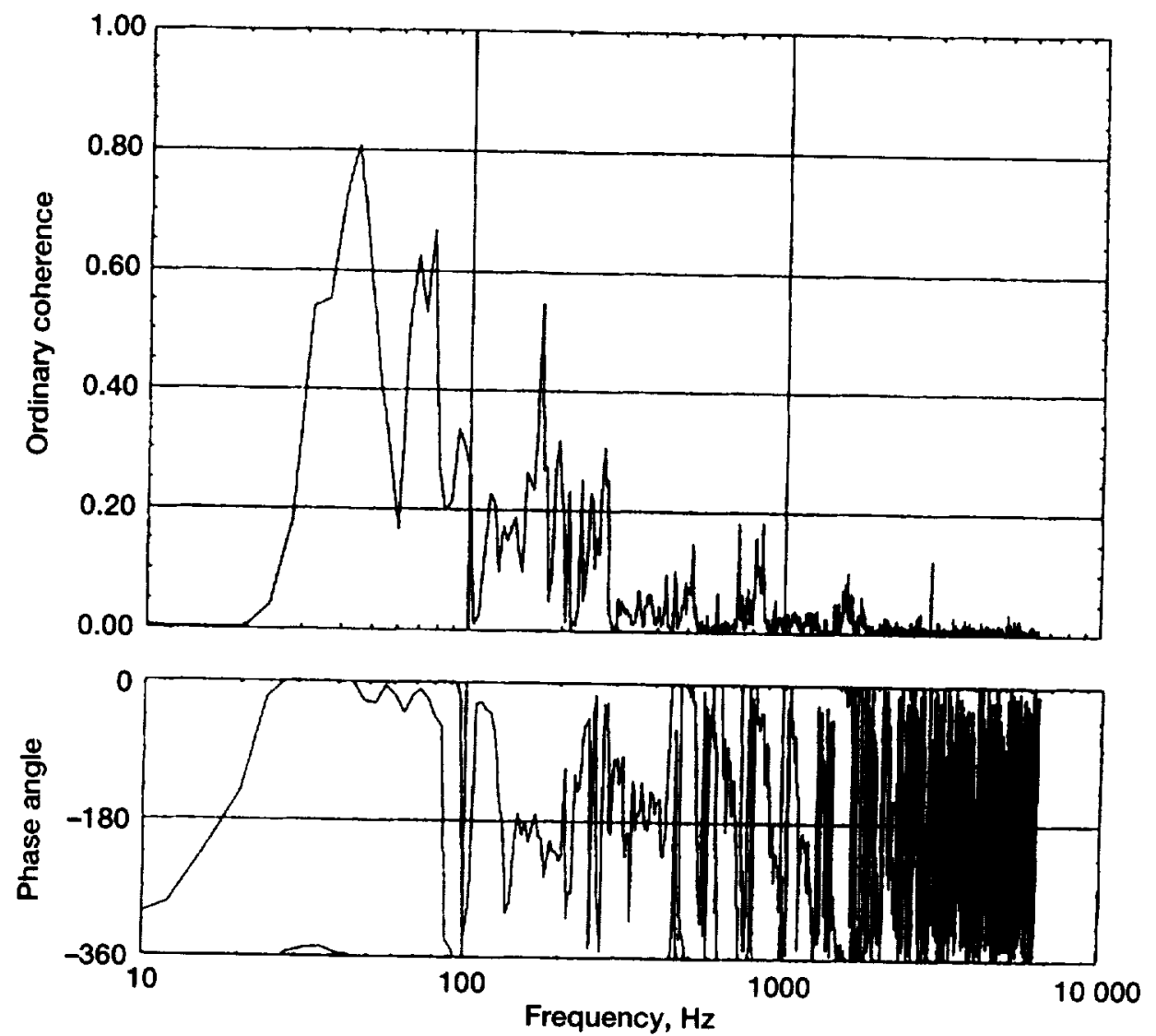

Figure 6 \& 7.-Coherence spectrum and phase angle for Microphones 4 and 6 on opposite sides of the Cassini HGA during reverberant acoustic Phase 2 Test 7.

of the structure by using a perimeter baffle around the HGA. However at $43 \mathrm{~Hz}$, coherence of $\gamma^{2}{ }_{(4.6)}=0.8$ shows significant coupling of the two fields. Figure 7 shows zero phase of the cross-spectrum at $43 \mathrm{~Hz}$, indicating the instantaneous pressures across the HGA should be subtracted and the net structural loading reduced. These results have significant implication on future acoustic testing of large antennae and reflectors.

Figure 8 shows high coherence between 30 and $250 \mathrm{~Hz}$ for internal microphone pair $(23,24)$ near one of the RTGs. Microphone 24 is located adjacent to the PLF/blanket (6-in. from PLF) and microphone 23 is 18 in. from the PLF. Figure 9 shows close to zero phase between these two frequencies. Thus, below $250 \mathrm{~Hz}$, the direct progressive acoustic field dominates. Low coherence below $25 \mathrm{~Hz}$ is probably due to electrical noise contribution. Above $250 \mathrm{~Hz}$, low coherence indicates a reverberant field.

A complete summary of the full scale cylindrical PLF testing may be found elsewhere (refs. 2, 4 to 12).

\section{Cassini Blanket Selection}

The technical assessment of the Phase 2 test data is that both the V5 and V10 barrier blankets had similar acoustic performances, exceeding the goal of reducing the acoustic environment by $3 \mathrm{~dB}$ and significantly reducing the RTG vibration response, at the key frequencies of 200 and $250 \mathrm{~Hz}$. No detrimental effects were seen at any frequency or in other PLF zones.

NASA Glenn's Cassini Project Office selected V5 for the Cassini mission. Factors considered, besides the acoustic improvement, were the added weight of the blankets, and contamination, separation, thermal, venting, and clearance factors. With most of these considerations being nearly equal, the weight of the blanket became the deciding factor and the "lighter" V5 blanket was chosen over the heavier V10. The V5 blanket is 4 times the weight of the Titan IV baseline. 

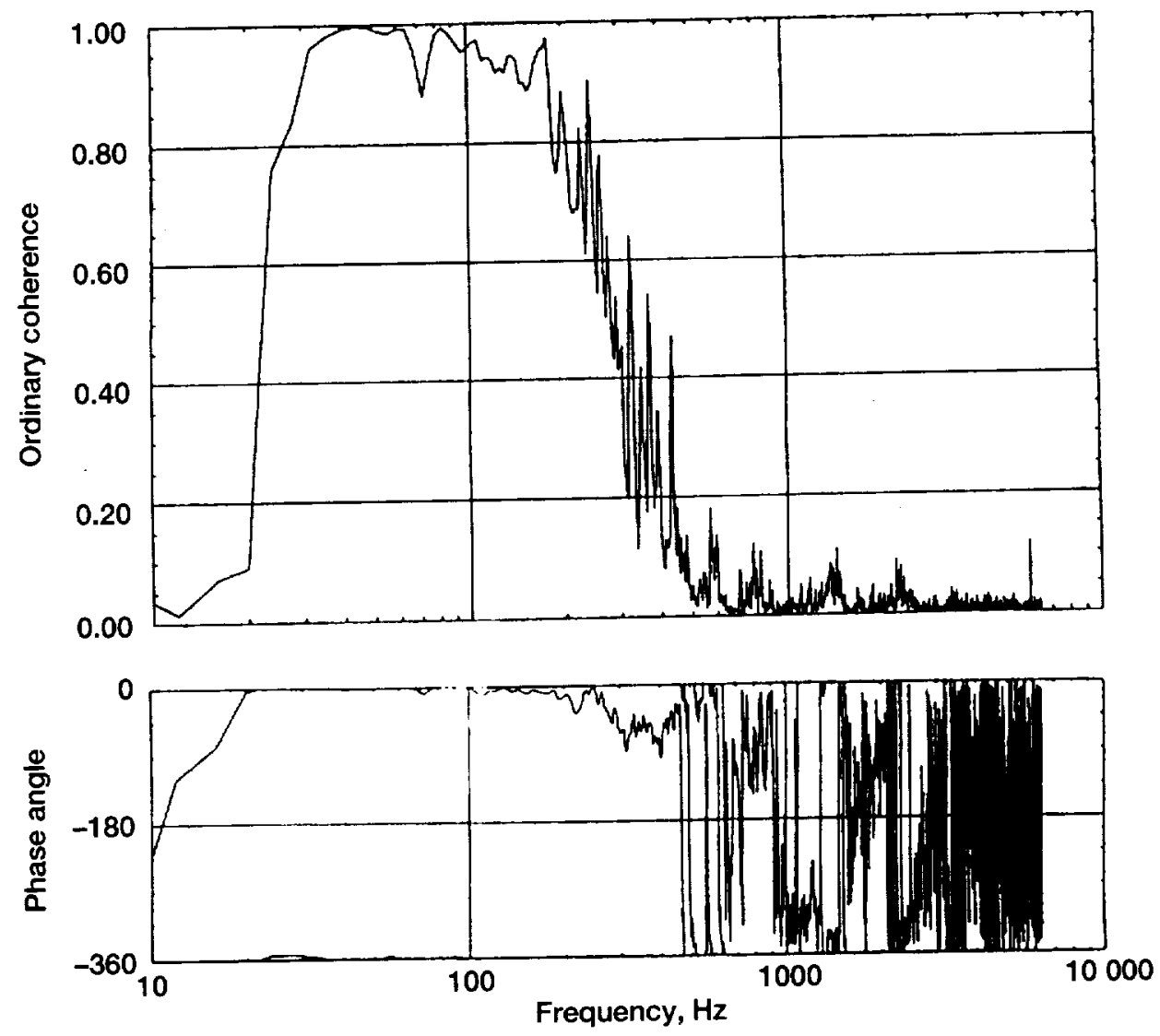

Figure 8 \& 9.-Coherence spectrum and phase angle for Microphones 23 (18-in. standoff) and 24 (PLF surface mounted) during reverberant acoustic Phase 2 Test 7.

\section{Cassini Flight Instrumentation}

Cassini was successfully launched from Cape Canaveral Air Force Station Space Launch Complex 40 on October 15, 1997 on Titan IV Vehicle B-33.

Flight data (ref. 13) was provided by LMA's Pulse Coded Modulation (PCM) Wideband Instrumentation System (WIS). Out of 32 high frequency channels, 10 acoustic measurements were made, consisting of 6 internal PLF measurements, 2 external PLF measurements and 2 external measurements on the Titan IV compartment $2 \mathrm{~A}$. The locations and descriptions of these are provided in table 1 and in figure 10. Internal measurements 10003, 10004, 10005 and 10006 were considered Cassini mission unique measurements.

LMA analysts calculated $1 / 3$ octave band (OB) sound pressure levels (SPL), in $\mathrm{dB}$, for these microphones. Liftoff SPL were calculated from the maximum envelopes of $1 \mathrm{sec}$ time averages, with 50 percent overlap, over the 0 to $8 \mathrm{sec}$ duration of the event.

\section{Cassini Flight Data Analysis}

Figure 11 shows the 1/3 OB SPL of all valid acoustic data measured during the Cassini liftoff, plus some reference specifications. The higher family of curves represents the external flight data and the lower family shows the affect of the acoustic blankets and the PLF structure's noise reduction on the internal flight levels. One external measurement (9121) has a lower SPL, due to its $90^{\circ}$ azimuth and shielding from the SRMU (Solid Rocket Motor Upgrade). LMA's maximum predicted P95/50 specification at the surface for a Titan IV with SRMU baselines the external flight data. 


\begin{tabular}{|c|c|}
\hline $\begin{array}{c}\begin{array}{c}\text { Measurement } \\
\text { number }\end{array} \\
\end{array}$ & Description \\
\hline 9102 & $\begin{array}{l}\text { External, PLF Station 104. Azimuth } 0 \\
\text { Centaur region }\end{array}$ \\
\hline 9103 & $\begin{array}{l}\text { External. PLF Station 104, } \\
\text { Azimuth 180. Centaur region } \\
\text { Measurement Data considered Invalid } \\
\end{array}$ \\
\hline 9104 & $\begin{array}{l}\text { Internal, PLF Station 312, Azimuth } 0 \\
\text { Near the Centaur Forward Adapter } \\
\end{array}$ \\
\hline 9105 & $\begin{array}{l}\text { Internal, PLF Station 312, Azimuth } 180 \\
\text { Near the Centaur Forward Adapter } \\
\end{array}$ \\
\hline 9121 & $\begin{array}{l}\text { External. TIV Station } 240, \text { Azimuth } 90 \\
\text { Compartment 2A region } \\
\end{array}$ \\
\hline 9122 & $\begin{array}{l}\text { External. TIV Station } 240, \text { Azimuth } 0 \\
\text { Compartment } 2 \text { A region } \\
\end{array}$ \\
\hline 10003 & $\begin{array}{l}\text { Internal. PLF Station572, Azimuth } 10 \\
18 " \text { Standoff above Cassini HGA }\end{array}$ \\
\hline 10004 & $\begin{array}{l}\text { Internal, PLF Station 521, Azimuth } 10 \\
18 * \text { Standoff below Cassini HGA }\end{array}$ \\
\hline 10005 & $\begin{array}{l}\text { Internal, PLF Station 335. Azimuth } 10 \\
18^{* \prime} \text { Standoff near Cassini RTG }\end{array}$ \\
\hline 10006 & $\begin{array}{l}\text { Internal. PLF Station 335, Azimuth } 10 \\
\text { Surface Mounted near Cassini RTG }\end{array}$ \\
\hline
\end{tabular}

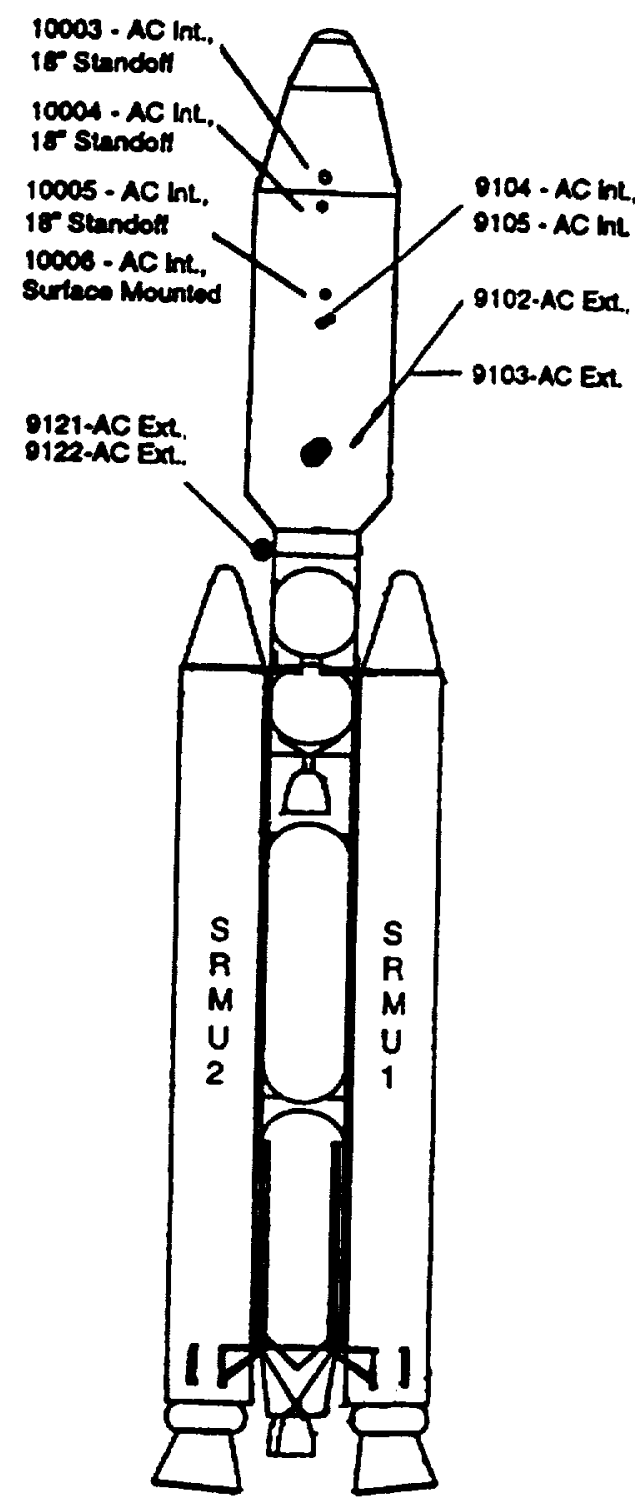

Figure 10.-Acoustic flight measurement locations for Titan IV B-33. ${ }^{13}$

Prior to launch, the Cassini spacecraft and its hardware were qualified for flight by acoustic and random vibration testing. There were two acoustic specifications in the Cassini Interface Control Document (ICD), one for the spacecraft and another for the RTGs. The ICD specified the maximum predicted P95/50 free-field PLF internal environment (fig. 11). The RTG ICD specification is lower below $500 \mathrm{~Hz}$, due to usage of the improved blankets in the $\mathrm{RTG}$ region.

The actual flight acoustic levels did fall below the ICD levels. Microphone 10006, which approached the RTG ICD level at $250 \mathrm{~Hz}$, is PLF surface mounted and thus its SPL is higher than the PLF's interior levels.

Figure 12 shows the comparison of 3 Cassini PLF interior flight measurements versus preflight predictions (refs. 11 and 14). The prediction was derived by statistically analyzing 22 measurements from 8 previous Titan IV flights to determine the mean and P95/50 levels for a typical Titan IV flight with the standard SRM (Solid Rocket Motor) and baseline blankets. To get the Cassini predictions, these earlier predictions were adjusted for the SRMU effect ( $1 \mathrm{~dB}$ added) and the expected decrease in SPL resulting from the utilization of V5 blankets (fig. 5). The measured flight data (10004, 10005 and 10006 (corrected to an 18-in. free field level)) approximated the predicted mean up to $300 \mathrm{~Hz}$, was lower than the mean between 300 to $1000 \mathrm{~Hz}$ and was significantly lower than the predicted mean above $1000 \mathrm{~Hz}$. 


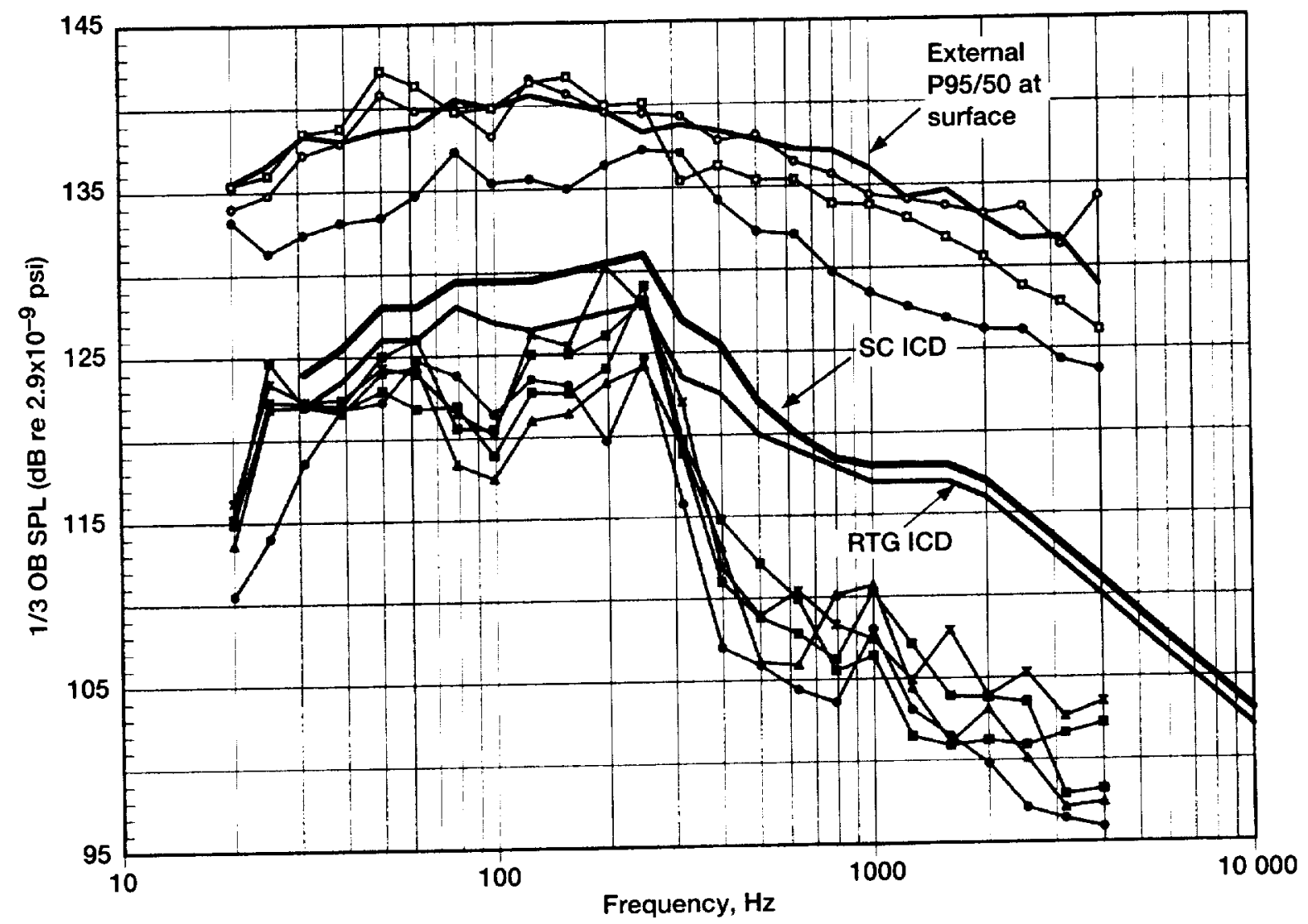

Figure 11.-Cassini acoustic flight data at liftoff.

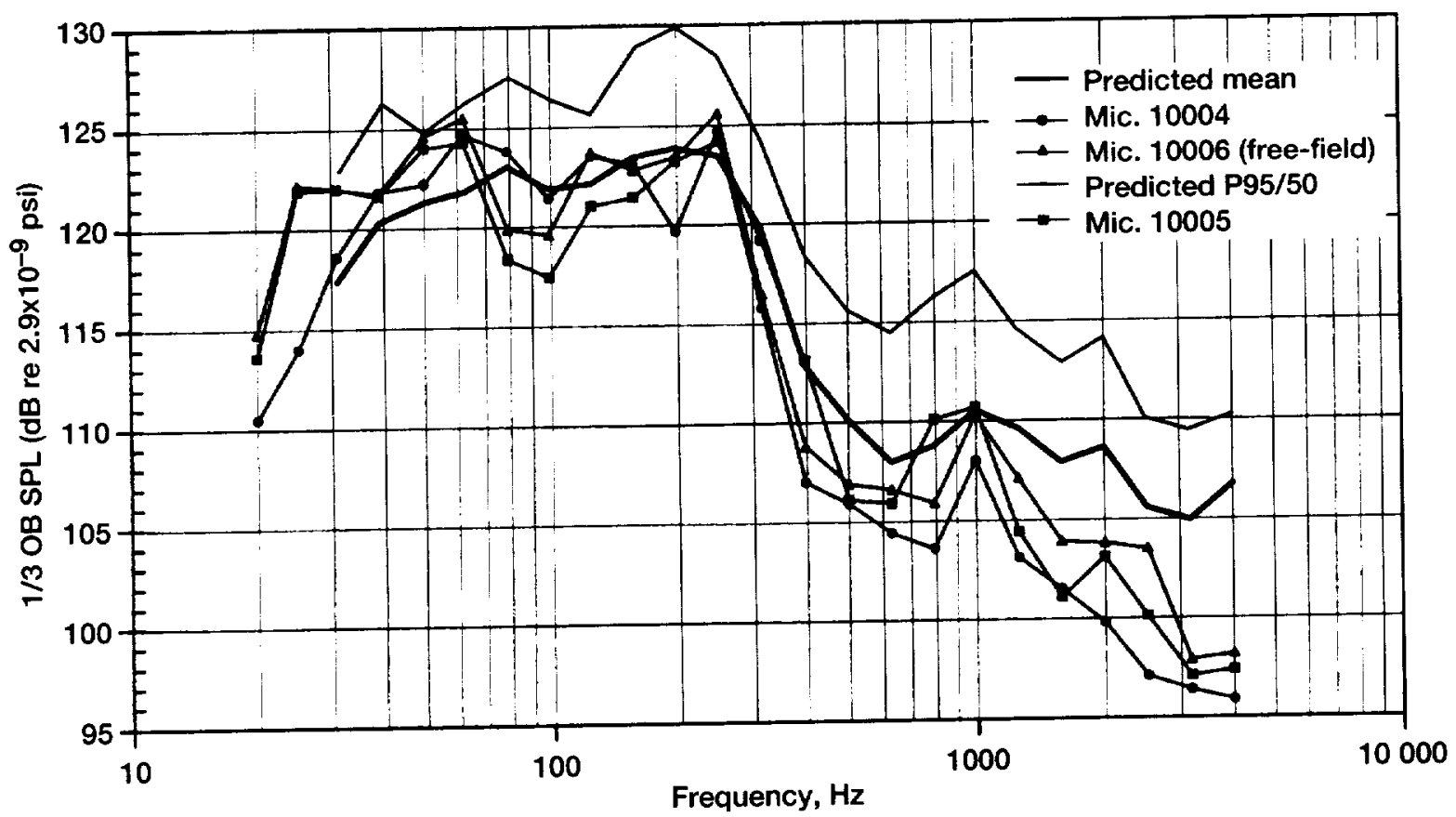

Figure 12.-Cassini PLF internal flight data versus pre-flight prediction. 


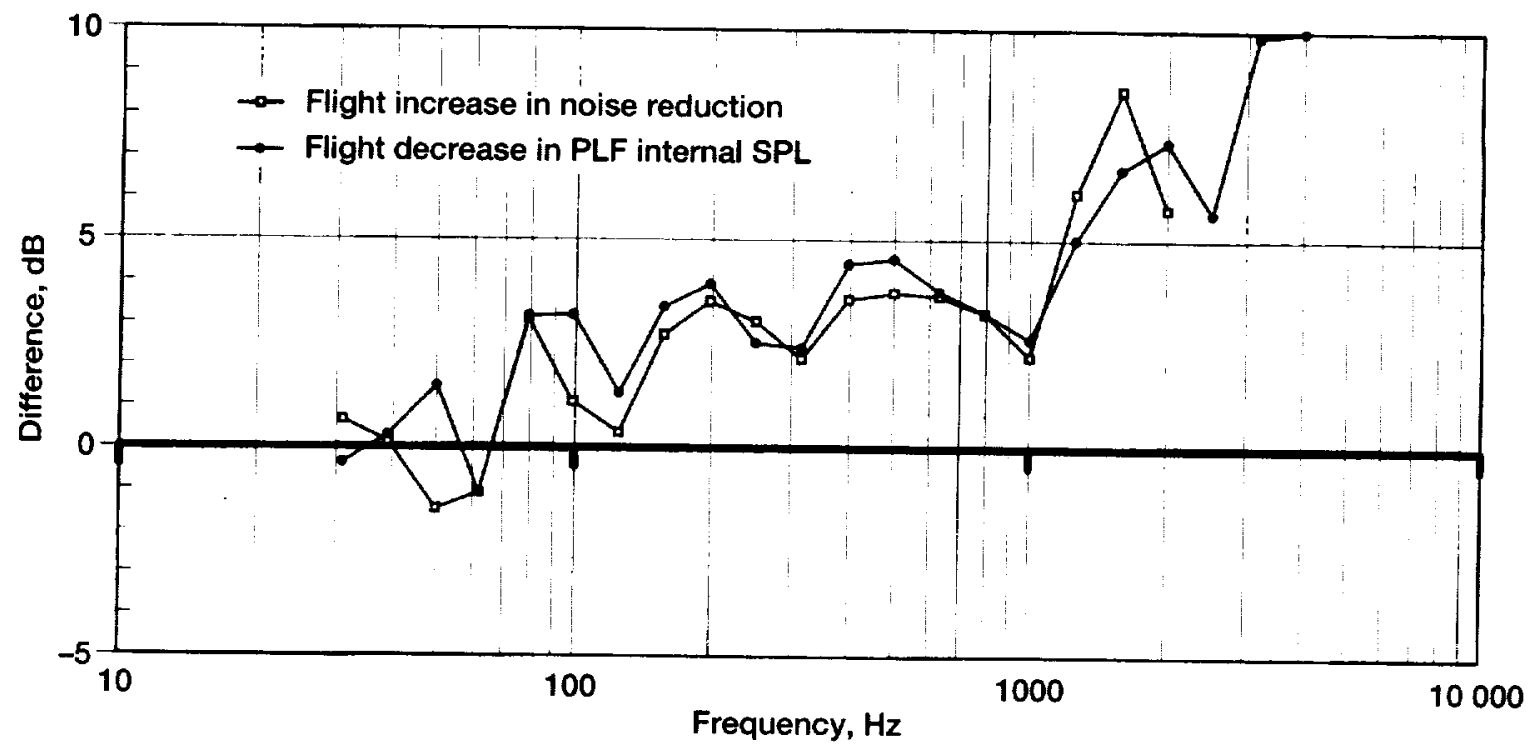

Figure 13.-Measures of acoustic improvement observed in Cassini flight.

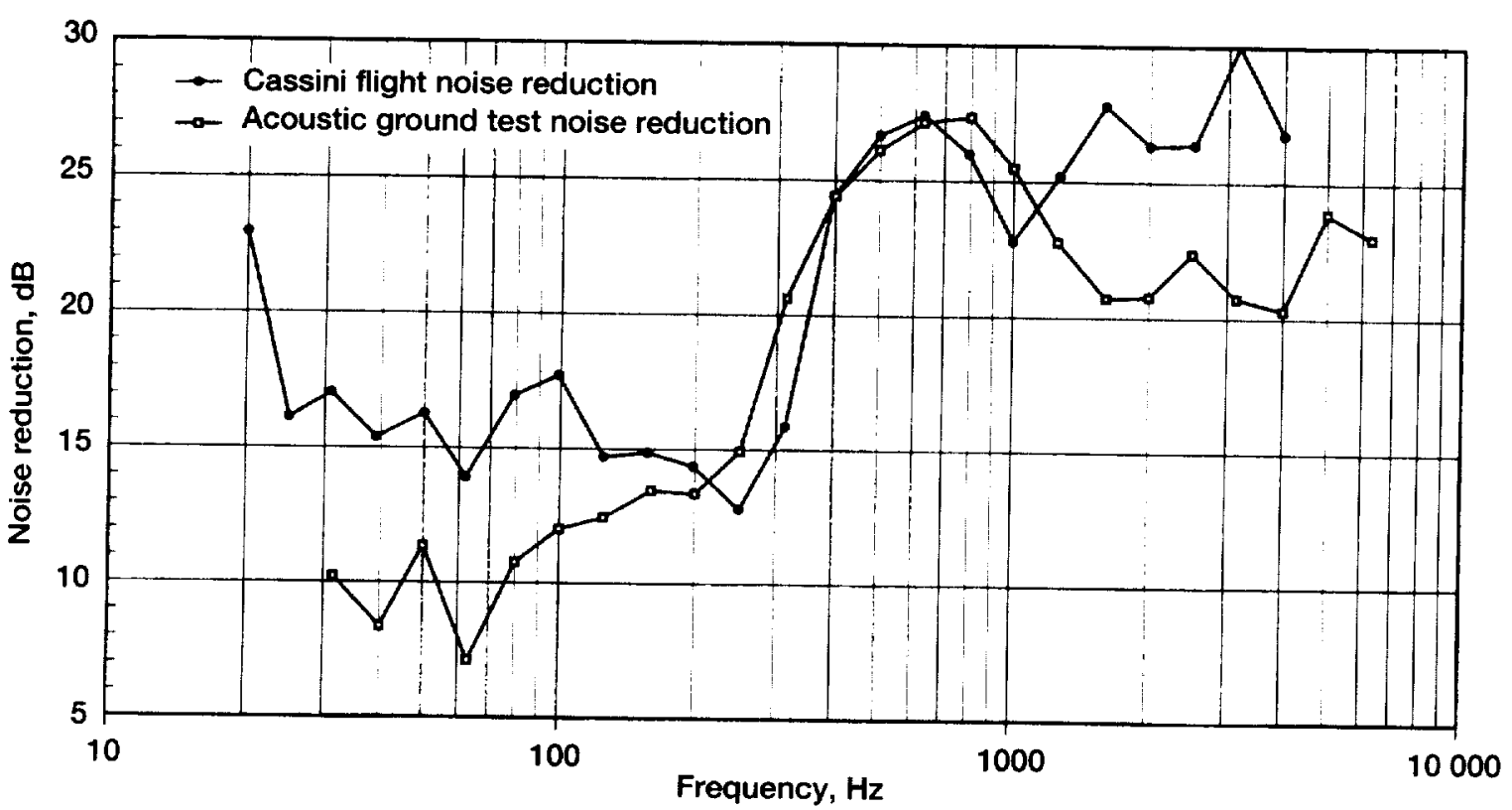

Figure 14.-Noise reductions for Titan VI PLF with V5 blankets.

The real flight performance was actually better, since this analysis assumed that Cassini was a nominal Titan IV flight. As seen from figure 11 , the Cassini external flight levels were somewhat greater than nominally expected exceeding the $\mathrm{P} 95 / 50$ level in the $50,63,125$ and $160 \mathrm{~Hz} 1 / 3 \mathrm{OB}$. The difference, seen in figure 13, between the predicted and flight measured PLF interior levels, adjusted for a nominal external flight level, shows that the interior flight levels were better than the expected levels based on prior flight data.

Figure 13 also shows another curve, which is the improvement seen in flight derived from a comparison of the flight and ground test noise reductions (fig. 14). The ground test noise reduction is from the Phase 2 test and is the difference between the external and interior PLF levels in PLF Zones 9 to 10. The flight noise reduction is the difference between an adjusted external flight level of microphone 9102 and the mean of three flight PLF interior microphones (10004, 10005 and an 18-in. free field adjusted 10006). The adjustments to the external flight level were to account for microphone 9102 being at $0^{\circ}$ azimuth and surface mounted. 


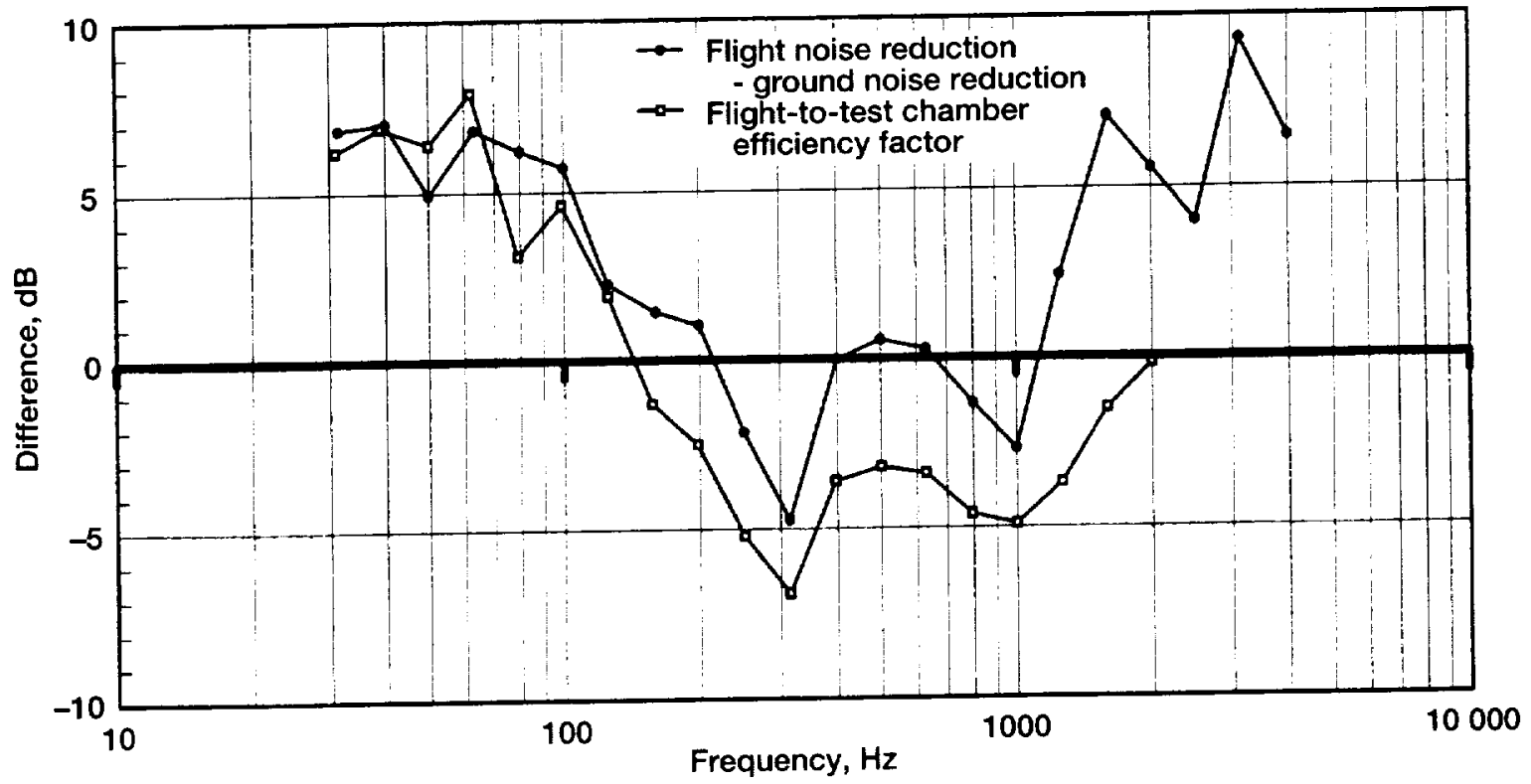

Figure 15.-Comparison of flight-to-ground levels.

The difference between the flight and ground test noise reductions is given in figure 15 , indicates that greater noise reduction was obtained in flight below $200 \mathrm{~Hz}$ and above $1250 \mathrm{~Hz}$. However it is known that the PLF structure transmits acoustics differently when excited by a reverberant acoustic field (ground test) than when excited by a grazing incidence progressive acoustic field (at liftoff). A flight-to-test chamber efficiency factor derived by Bradford and Manning (ref. 7) is also plotted in figure 15. Subtract this factor from measured ground test data to compute equivalent flight levels.

The difference between the two curves in figure 15 gives a measure of "improvement observed in flight." This improvement is very close to the improvement in PLF interior levels discussed earlier. These two flight improvements are compared in figure 13 and together can be considered a measure of improvement obtained in flight over that predicted.

The next issue analyzed was the difference between surface and standoff mounted microphones, and how this comparison varies from flight to ground. For the Cassini flight, measurement 10005 was mounted on an 18-in. standoff from the PLF inner wall, whereas 10006 was a surface mounted microphone (actually mounted on a short 6 -in. standoff due to the blanket thickness). In the full-scale Cassini ground test, a similar pair of microphones (23 and 24) was also mounted at standoffs of 18- and 6-in., respectively, at the same PLF station. Figure 16 shows a delta comparison of how "surface" mounted measurements compared with 18-in. standoff measurements in flight versus ground. Below $250 \mathrm{~Hz}$, the SPL measurement near the surface is greater than the free-field SPL measurement. The flight delta follows the ground test delta spectrally within $1 \mathrm{~dB}$ below $250 \mathrm{~Hz}$. Above $250 \mathrm{~Hz}$, and the corresponding smaller wavelengths, the delta of the measurements and their comparison becomes more irregular.

High coherence and nearly zero phase below $250 \mathrm{~Hz}$ was observed in figures 17 and 18 , respectively for flight microphone pair 10005 and 10006 . These measurements generally confirm similar data (figs. 8 and 9) obtained during Phase 2 ground testing. This conclusion is reached despite the fact the external acoustic field during ground testing was reverberant, whereas during the flight the field was progressive.

Another comparison between flight and ground test measurements is how the acoustic levels compared above and below the HGA. In the full-scale acoustic ground test, microphone 6 was below and microphone 4 was above the HGA. For the Cassini flight, microphone 10004 was below and 10003 was above the HGA, at the same respective PLF stations as the ground tests microphones. All four microphones were on 18-in. standoffs. The flight measurement pair was at azimuth $0^{\circ}$ and the ground test measurement pair was at azimuth $60^{\circ}$, but the effect of this should be small, as the PLF interior acoustics is a reverberant field.

A comparison of the SPL difference between the measurements (below minus above) is shown in figure 19, for both the flight and ground test measurements. In general, the SPLs below the HGA (cylindrical section) are higher than the levels above the HGA (conical section). Spectrally the shape of the deltas is similar for ground and flight data. However, the ground test delta is typically larger, indicating that more "mixing" occurs in flight between the acoustic volumes above and below the HGA. 


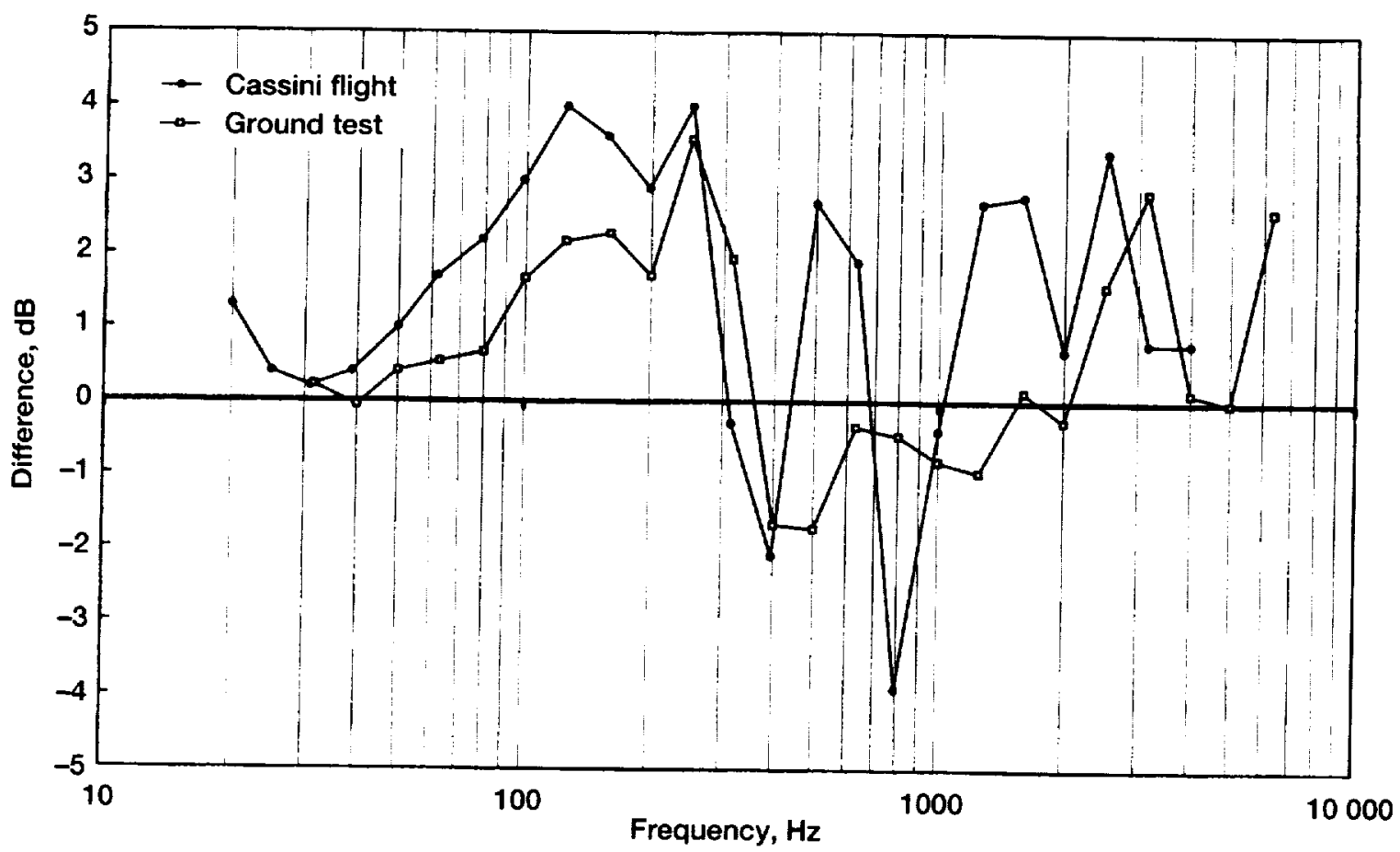

Figure 16.-Deltas between SPL measurements (surface mounted minus 18-in. standoff).
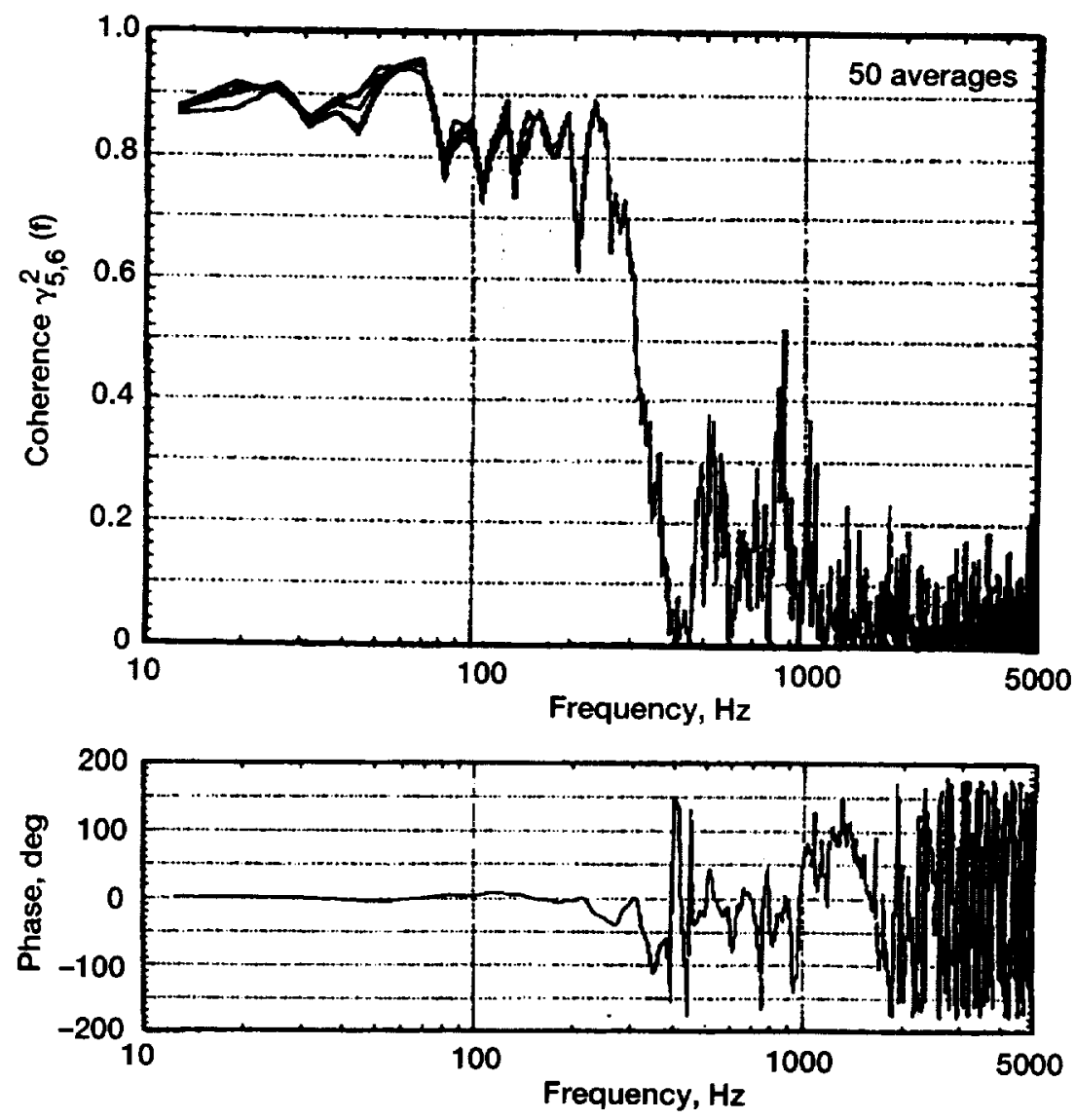

Figure $17 \& 18$. - Coherence spectrum and phase angle for Microphones 10005 (18-in. standoff) and 10006 (PLF surface mounted) during Cassini flight liftoff. 


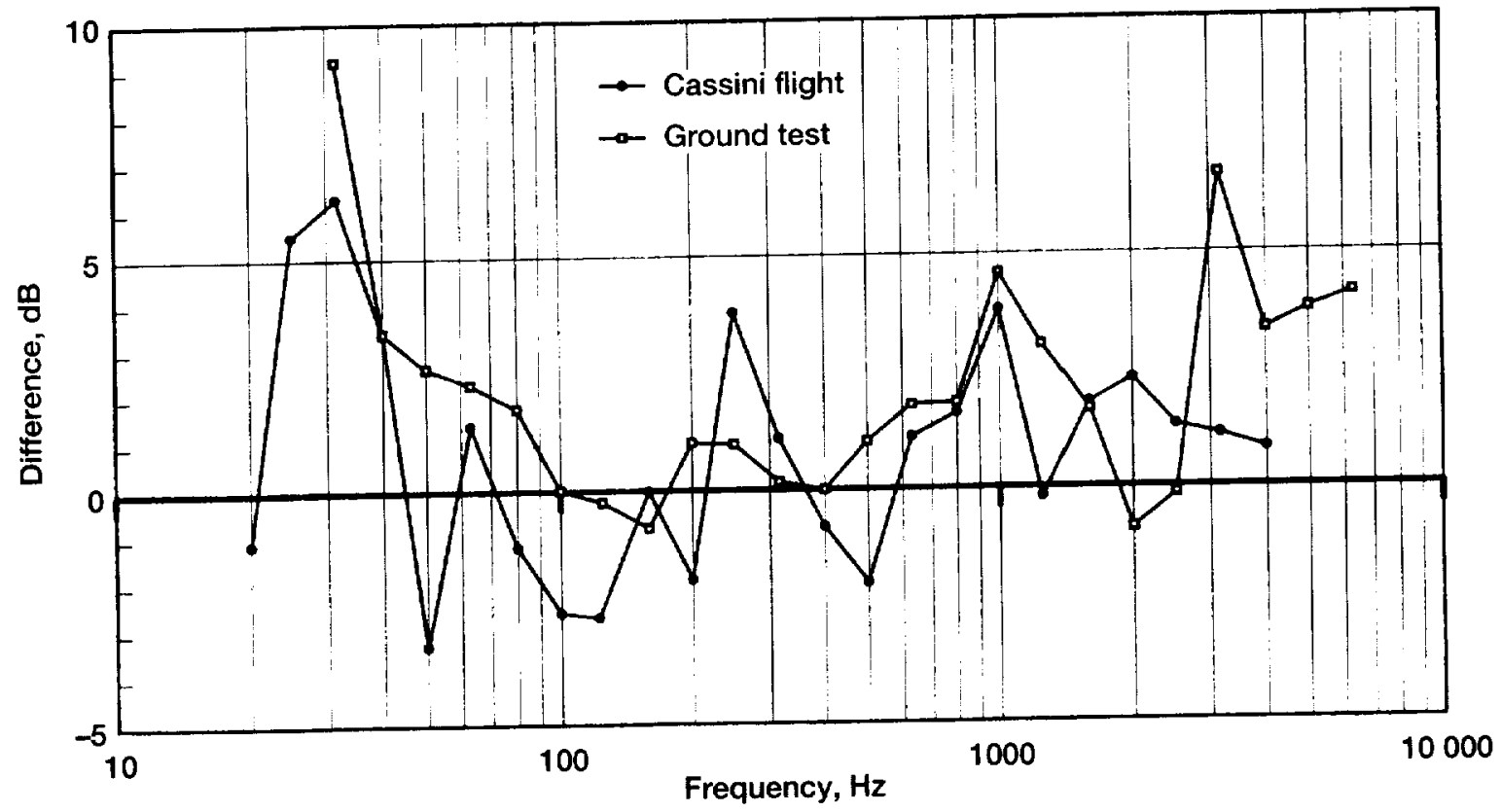

Figure 19.-Deltas between SPL measurements (below HGA minus above HGA).
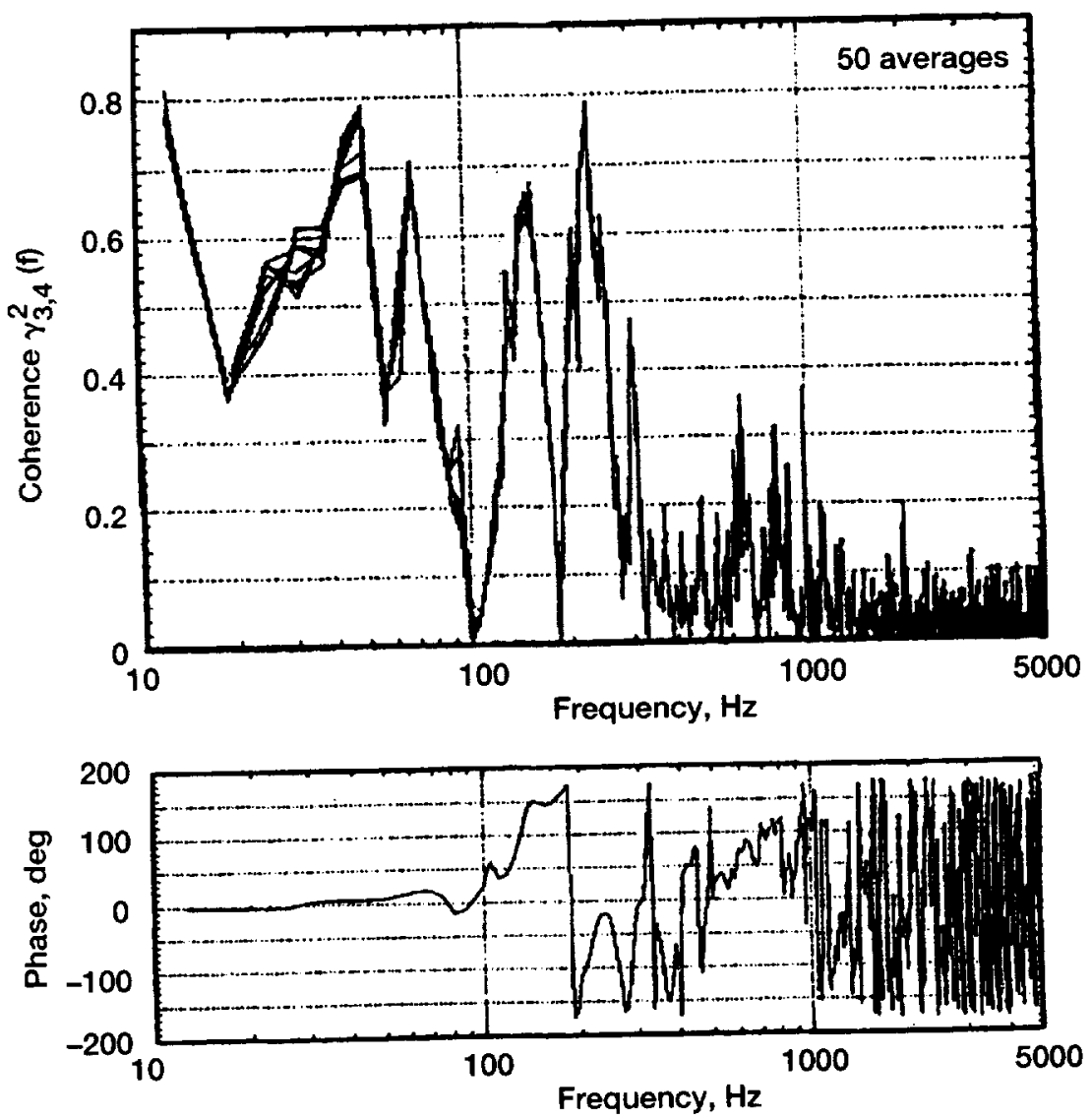

Figure 20 \& 21.-Coherence spectrum and phase angle for Microphones 10003 and 10004 on opposite sides of the Cassini HGA during Cassini flight liftoff. 
Flight coherence data, similar to that obtained during Phase 2 acoustic ground testing (see figs. 6 and 7), were also examined. Flight coherence data were obtained using $5-\mathrm{sec}$ time windows to allow for the nonstationarity of the liftoff event. Figure 20 again shows low coherence, except at 50 and $230 \mathrm{~Hz}$. Figure 21 shows nearly zero phase at these latter two frequencies.

\section{Conclusions}

Cassini measurements, both on the ground and during launch provided the opportunity to investigate the spacecraft's acoustic field. Extensive testing was performed in a reverberant acoustic full-scale ground test primarily to address the acoustic performance of improved acoustic blankets. These tests verified that the new acoustic blankets met the goal of reducing the PLF interior acoustics in the zones of interest by $3 \mathrm{~dB}$ or more at the Cassini critical frequencies of 200 and $250 \mathrm{~Hz}$. The V5 blankets were selected and flew successfully on the Cassini mission. Due to the improved acoustic blankets, the Cassini's RTGs did not have to be vibration requalified, resulting in $\$ 30$ Million in savings for NASA and the taxpayers.

The thoroughness and planning involved with the ground test program resulted in excellent results and greatly contributes to the aerospace industry's knowledge of acoustics. The four Cassini flight measurement locations were duplicated in the acoustic ground test. This allowed the SPL generated in flight by a progressive acoustic field to be compared with the SPLs generated on the ground by the reverberant acoustic field. Flight microphones were also chosen to investigate the effect of a large structure (HGA) on the PLF"s interior acoustics, and the effect of standoff distance of the microphone from the PLF wall. The delta difference in SPL and the coherence and phase for these pairs of microphones compared very well for flight versus ground and adds to the knowledge base.

In addition, two different methods were used to provide a measure of "improvement" in flight over ground and preflight predictions. This indicated that the PLF interior acoustic levels were lower than expected for the Cassini flight. Thus it can be said performing a thorough acoustic reverberant ground test program can qualify a spacecraft for its flight environment by a conservative amount.

\section{References}

1. Armel, T.L.: "Titan IV Payload Fairing S/N 000036 Acoustics Flat Panel Tests," McDonnell Douglas Aerospace-Sp. Syst. Rpt. MDC 94H0067, July 1994.

2. Hughes, W.O., McNelis, A.M.: "Cassini/Titan IV Acoustic Blanket Development and Testing," Proc. $42^{\text {nd }}$ ATM, Inst. Envir. Sc., May 1996, NASA TM-107266.

3. Himelblau, H., Piersol, A.G., Wise, J.H., Grundvig, M.R.: "Handbook for Dynamic Data Acquisition and Analysis," IEST Recommended Practice DTE 012.1, Sec 5, May 1994.

4. Hughes, W.O., McNelis, A.M.: "Acoustic Testing of the Cassini Spacecraft and Titan IV Payload Fairing, Part 1. Introduction and Test Configuration, Part 2. Results," $67^{\text {th }}$ Shock \& Vibration Symposium, November 1996, NASA TM-107474 and 107475.

5. Bradford, L., Sayuk, T., Jack, A.: "Cassini Payload Fairing (PLF) Acoustic Blanket Test, Part A: Test Plan, Part B: Test Report," Lockheed Martin Report NAS3-00014, October 1995.

6. Hebert, B.F., Manning, J.E.: "Cassini Acoustic Blanket Test Program," Cambridge Collaborative Report 95-2-12485-2, February 1996.

7. Bradford, L., Manning, J.E.: “Acoustic Blanket Effect on Payload Acoustic Environment," Proc. 42 ${ }^{\text {nd }}$ ATM, Inst. Envir. Sc., May 1996.

8. Bergen, T.F., Kern, D.L.: "Attenuation of Cassini Spacecraft Vibroacoustics Environment," Proc. $42^{\text {nd }}$ ATM, Inst. Envir. Sc., May 1996.

9. Bergen, T.F.: "Cassini Partial-DTM/Titan IV Payload Fairing (PLF) Acoustic Test Report," JPL IOM 352D-95-102, July 1995.

10. Long, M.B., Carne, D.A., Fuller, C.M.: "Acoustic Blanket Effect on Payload Fairing Vibration," Proc. 42 $2^{\text {nd }}$ ATM. Inst. Envir. Sc., May 1996. 
11. Bergen, T.F., Himelblau, H., Kern, D.L.: "Development of Acoustic Test Criteria for the Cassini Spacecraft," IEST, Vol.41, No. 1, January/February 1998.

12. Bergen, T.F., Kern, D.L.: "RTG Vibration TVA Assessment," Titan IV Cassini Vibroacoustics Technical Interchange Meeting, March 1995.

13. Elliot, K., Salem, L.: “Titan IVB-33 Flight Report Wide Band Instrumentation System (WIS) High Frequency Channels," MCR-0001-0041, December 1997.

14. Bergen, T.F., Himelblau, H., Kem, D.L.: "Cassini Spacecraft Acoustic Flight and Test Criteria," Noise-Con 96. September/October 1996. 


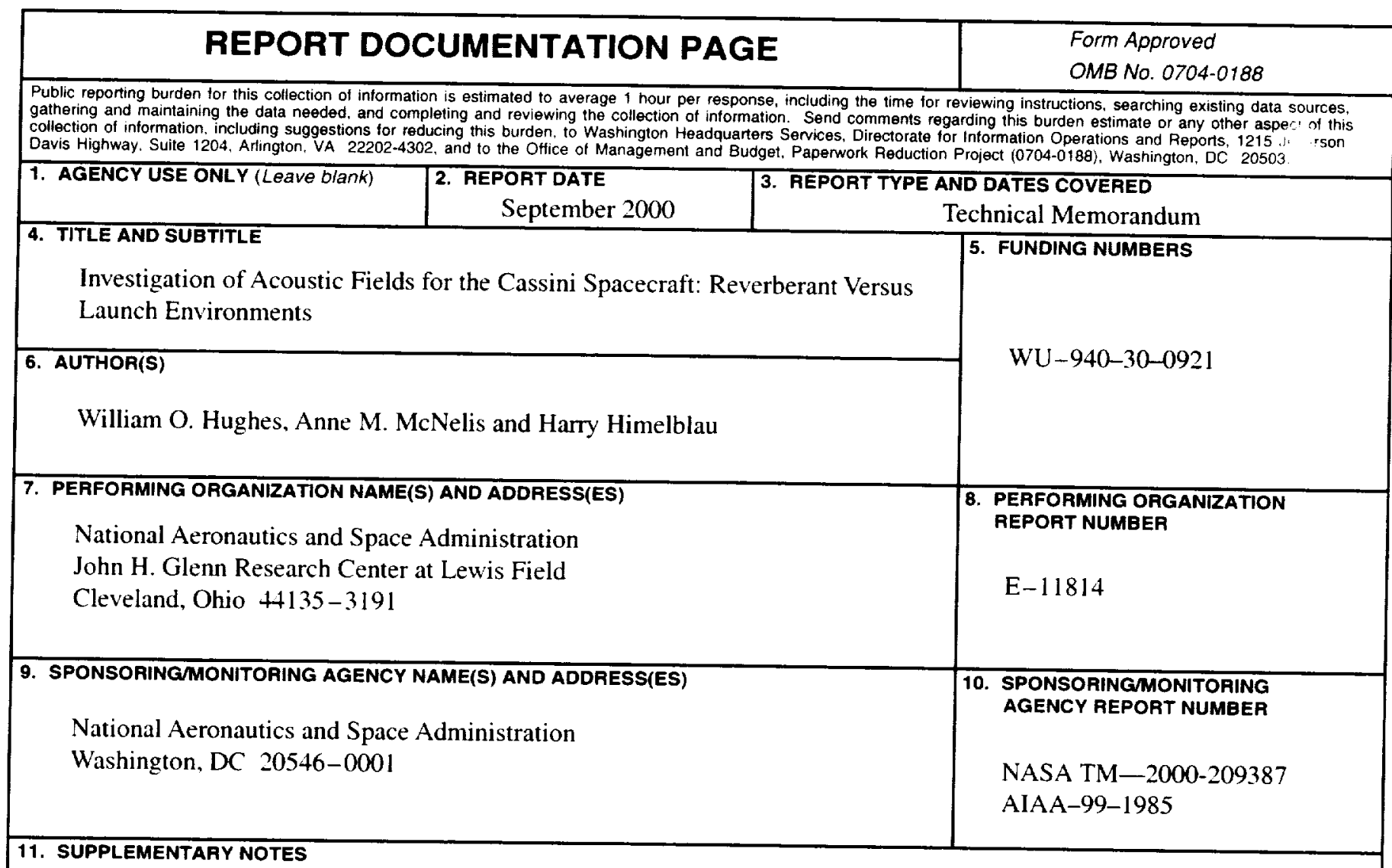

Prepared for the 5th Aerocoustics Conference and Exhibit cosponsored by the American Institute of Aeronautics and Astronautics and the Confederation of European Aerospace Societies, Bellevue, Washington, May 10-12, 1999. William O. Hughes and Anne M. McNelis, NASA Glenn Research Center; Harry Himelblau, Rocketdyne/Boeing N.A., Canoga Park, California. Responsible person, William O. Hughes, organization code 7735, (216) 433-2597.

12a. DISTRIBUTION/AVAILABILITY STATEMENT

Unclassified - Unlimited

Subject Categories: 15, 18 and 71

Distribution: Nonstandard

This publication is available from the NASA Center for AeroSpace Information. (301) 621-0390.

13. ABSTRACT (Maximum 200 words)

The characterization and understanding of the acoustic field within a launch vehicle's payload fairing (PLF) is critical to the qualification of a spacecraft and ultimately to the success of its mission. Acoustic measurements taken recently for the Cassini mission have allowed unique opportunities to advance the aerospace industry's knowledge in this field. Prior to its launch, the expected liftoff acoustic environment of the spacecraft was investigated in a full-scale acoustic test of a Titan IV PLF and Cassini simulator in a reverberant test chamber. A major goal of this acoustic ground test was to quantify and verify the noise reduction performance of special barrier blankets that were designed especially to reduce the Cassini acoustic environment. This paper will describe both the ground test and flight measurements, and compare the Cassini acoustic environment measured during launch with that measured earlier in the ground test. Special emphasis will be given to the noise reduction performance of the barrier blankets and to the acoustic coherence measured within the PLF.

\section{SUBJECT TERMS}

Acoustics: Spacecraft testing

17. SECURITY CLASSIFICATION
OF REPORT
Unclassified

18. SECURITY CLASSIFICATION OF THIS PAGE

Unclassified
19. SECURITY CLASSIFICATION OF ABSTRACT Unclassified

NSN 7540-01-280-5500

15. NUMBER OF PAGES 21

16. PRICE CODE

$\mathrm{A03}$

20. LIMITATION OF ABSTRACT


